\section{Representações sociais do corpo: um estudo com adolescentes do Município do Rio de Janeiro, Brasil}

\author{
Social representations of the body: a study of \\ adolescents in the city of Rio de Janeiro, Brazil
}

Las representaciones sociales del cuerpo: un estudio de los adolescentes en la ciudad de Río de Janeiro, Brasil
Michelle Delboni dos Passos 1,2 Sílvia Ângela Gugelmin 2,3 Inês Rugani Ribeiro de Castro 2 Maria Claudia da Veiga Soares Carvalho 2,4
1 Instituto de Nutrição Annes Dias, Rio de Janeiro, Brasil. 2 Universidade do Estado do Rio de Janeiro, Rio de Janeiro, Brasil.

3 Universidade Federal do Mato Grosso, Cuiabá, Brasil. 4 Universidade Federal do Rio de Janeiro, Rio de Janeiro, Brasil.

Correspondência M. D. Passos

Instituto de Nutrição Annes Dias.

Av. Pasteur 44, Rio de janeiro, $R$ 22290-240, Brasil.

midelboni@yahoo.com.br

\begin{abstract}
Body changes are central to adolescence as a stage of life. To approach conflicts experienced by adolescents with body changes, this study aimed to identify social representations of the body among adolescents in the last year of primary school in private and municipal schools in Rio de Janeiro, Brazil. Participants were 13 to 18 years of age and studied in schools in neighborhoods with the highest and lowest scores on the Social Development Index. Focus groups were used to produce social representation of the body. Groups began by evoking five words that came to mind when hearing the word "body". The EVOC program was used to treat evoked words, complemented by thematic content analysis. Many teenagers spoke of "beauty" as synonymous with "beautiful body" and described a model of beauty: a muscular body for teenage boys and a slender and shapely body for teenage girls.
\end{abstract}

Body Image; Adolescent; Focus Groups

\section{Resumo}

A adolescência é uma das fases da vida em que as alterações corporais parecem assumir uma importância fundamental. Com o intuito de nos aproximarmos dos conflitos experimentados pelos adolescentes com as mudanças corporais, este estudo objetivou conhecer as representações sociais sobre o corpo entre estudantes do nono ano do ensino fundamental das redes privada $e$ municipal do Rio de Janeiro, Brasil. Os participantes tinham entre 13 e 18 anos de idade, e estudavam em escolas localizadas em bairros com mais alto e mais baixo valores do Índice de Desenvolvimento Social. Usamos a técnica de grupo focal para a produção da representação social do corpo. Iniciamos os grupos com a evocação de cinco palavras quando ouviam a palavra "corpo". Para o tratamento das evocações, utilizamos o programa EVOC e, para complementar, análise de conteúdo temática. Grande parte dos adolescentes falou da beleza como sinônimo de corpo bonito e descreveram um modelo de beleza: o corpo definido por músculos para os jovens e o corpo magro e curvilíneo para as jovens.

Imagem Corporal; Adolescente; Grupos Focais 


\section{Introdução}

A preocupação com a boa forma física e as práticas a ela associadas, como dietas, musculação, aceitação e valorização de si próprio atravessam todas as fases da vida. A suposta liberdade de escolha é dependente do padrão estético veiculado na mídia, que transforma o corpo em objeto de consumo e projeção de desejos e de medidas perfeitas $1,2,3$.

Segundo Wolf 4 , as indústrias da dieta e dos cosméticos são capazes de (re)criar modelos, como o de feminilidade associada à forma física. Hoje, ter um corpo magro representa sucesso, poder e status, levando cada vez mais à obsessão pela magreza. Como se o corpo necessitasse ser exposto para ser "aprovado" pelo outro. Em contrapartida, os "não atraentes" são discriminados e se sentem pressionados a encobrir seus corpos, reforçando o preconceito contra a obesidade e o corpo gordo. Esses são associados à preguiça, à lentidão e à falta de autocontrole, e considerados "culpados"; sem força de vontade para transformar um corpo "gordo" em um corpo "perfeito" 5,6.

É na adolescência que as alterações corporais parecem assumir uma importância fundamental, seja por preocupação com a própria aparência ou com o peso corporal. O corpo tatuado, com piercings, os implantes subcutâneos, as cicatrizes produzidas em alto relevo, os diferentes cortes de cabelo, as roupas e os acessórios fazem parte do visual do jovem que quer afirmar a sua identidade e encontra no corpo um "meio de expressão do eu" 5,7,8 e uma ferramenta de singularidade 9 .

As cirurgias plásticas, tidas antes como alternativas para os adultos em busca deste "corpo $e$ saúde perfeitos, juventude eterna e beleza ideal" 10 (p. 46), vêm ganhando espaço entre os adolescentes insatisfeitos com a sua forma física. De acordo com os dados da Sociedade Brasileira de Cirurgia Plástica (SBCP), de setembro de 2007 a agosto de 2008 73\% das cirurgias realizadas no Brasil tinham fins estéticos. Embora a maior parte das cirurgias tenha sido feita em pessoas que tinham entre 19 e 35 anos de idade (38\%), 6\% foram realizadas em pessoas com 13 a 18 anos 11 . É importante refletirmos sobre o fato de que estamos falando de adolescentes que, muitas vezes, não têm ainda o seu corpo "formado".

Essa ênfase na forma de se expressar por meio da aparência e a supervalorização do peso fazem com que a adolescência seja crítica para a instalação de distúrbios da imagem corporal, de comportamentos alimentares e práticas de controle de peso inadequadas 12,13 . Pesquisa realizada em 2007 no Município do Rio de Janeiro, Brasil, com jovens do nono ano de escolas municipais 14 e o estudo realizado em 2009 com este mesmo grupo etário em escolas públicas e privadas das capitais brasileiras e do Distrito Federal 15, apontaram prevalência relevante de estudantes que recorreram a práticas extremas para controle do peso (6,2\% e 6,9\%, respectivamente).

Para evitar as consequências da insatisfação com a imagem corporal, como os comportamentos de risco para o controle de peso, os transtornos alimentares e a possível culpabilização de si, é fundamental desenvolver pesquisas sociais que busquem identificar os valores, os códigos culturais e os sentidos construídos em torno da imagem corporal. Nesse sentido, este estudo teve como objetivo conhecer as representações sociais em torno do corpo, de adolescentes moradores do Município do Rio de Janeiro.

\section{Representações sociais}

Para trabalhar com representação social utilizamos Moscovici 16 como referencial. Esse autor desenvolve o conceito com base na vida cotidiana, identificando-a como um sistema de interpretação da realidade que organiza as relações do sujeito com o mundo, orientando suas condutas e comportamentos. Pode ser vista como senso comum. No entanto, nem tudo é representação social, ou seja, nem todo objeto é objeto de representação. Além disso, o objeto de representação de um grupo não necessariamente o é para outro. Para algo ter representação social é necessário que apresente alguma relevância no meio sociocultural do grupo estudado 17 .

Para auxiliar na interpretação das representações sociais, a teoria da representação social apresenta pelo menos três abordagens consideradas complementares: processual, relacional e estrutural. A abordagem adotada no presente trabalho é a do tipo estrutural, desenvolvida em 1976 por Jean-Claude Abric, e que se propõe a identificar a forma que a representação está organizada internamente. Segundo esse enfoque as representações sociais estão estruturadas pelos sistemas central e periférico e recebem o nome de Teoria do Núcleo Central 17.

O núcleo central consiste no elemento mais estável da representação, ou seja, é resistente a mudanças e confere a esta representação uma noção de rigidez e de permanência. Quando o elemento central se modifica, obrigatoriamente a representação também sofrerá alterações. Essa transformação inicia sempre pelos elementos periféricos e é ocasionada, por exemplo, pelas mudanças nas práticas sociais. Já os elementos que fazem parte do sistema periférico são complementares ao núcleo central. Embora façam parte da representação, não são suficientes para modificá-la, mas são responsáveis pela interface 
entre a realidade concreta e o núcleo central. Isso quer dizer que os elementos periféricos são mais sensíveis ao contexto e às histórias individuais e, consequentemente, mais flexíveis e móveis 17,18.

\section{Caracterização dos sujeitos}

Definimos como sujeitos deste trabalho os alunos matriculados, em 2010, no nono ano do ensino fundamental das redes privada e pública municipal do Rio de Janeiro. Nosso universo de pesquisa consistiu em adolescentes com idades entre 13 e 18 anos (com maior concentração daqueles com idades em torno de 14-15 anos) e a escola foi o local escolhido para a realização do estudo. A escolha pelo nono ano se deu com o objetivo de possibilitar aproximações dos resultados desta pesquisa com outros estudos já referenciados neste artigo 14,15.

A cidade do Rio de Janeiro está organizada em 34 Regiões Administrativas (RA), cada uma comportando um conjunto de bairros. Optamos por selecionar escolas entre aquelas que se localizavam em RA com valores extremos (mais altos e mais baixos) do Índice de Desenvolvimento Social (IDS), conforme o Censo Demográfico de 2000 (Instituto Brasileiro de Geografia e Estatística. http://www.ibge.gov.br/home/eastatistica/ populacao/censo2000/default.shtm, acessado em Fev/2009), com o intuito de garantir maior diversidade dos perfis socioeconômicos dos sujeitos estudados. A leitura desse índice foi realizada partindo do princípio que quanto mais alto o IDS (que varia de 0 a 1) melhores são as condições socioeconômicas e sanitárias do bairro. Isso quer dizer que estudamos jovens de bairros com os melhores e os piores índices sociais da cidade do Rio de Janeiro.

Para a seleção das escolas, procedemos da seguinte forma: na RA com maior e na com menor IDS, identificamos o bairro com maior e com menor Índice e buscamos estudar uma escola da rede privada e outra da rede pública municipal em cada um deles. Uma vez que na Lagoa, bairro com o maior IDS da sua RA, não havia escolas públicas municipais, selecionamos escolas do Leblon, que apresentava o segundo maior IDS e dispunha de escolas públicas e privadas 19 . No entanto, após sete tentativas de contato com escolas privadas localizadas nesse bairro, sem retorno, substituímos a escola privada do Leblon por uma no bairro da Gávea, vizinho ao Leblon, no qual também vivem famílias com poder aquisitivo elevado.

Também tivemos dificuldade em realizar a pesquisa em escola privada de Guaratiba (bairro com o IDS mais baixo do município). Embora tenhamos feito diversos contatos com diferentes escolas, não conseguimos retorno de nenhuma delas. Nesse caso, não foi possível substituir esse bairro por outro da mesma RA, uma vez que esta contava somente com dois bairros e já havíamos incluído uma escola do segundo bairro, que apresentava o IDS mais alto. Portanto, ao final, estudamos sete escolas localizadas nos bairros Leblon (apenas escola pública), Gávea (apenas escola privada), Vidigal (pública e privada), Guaratiba (apenas escola pública) e Pedra de Guaratiba (pública e privada) (Figura 1).

Num primeiro momento, fizemos uma visita a cada escola escolhida que concordou em participar do estudo a fim de expor os objetivos da pesquisa e suas etapas. O turno escolhido (manhã ou tarde) foi aquele que concentrava o maior número de turmas de nono ano. A direção da escola ficou responsável por entregar o Termo de Consentimento Livre e Esclarecido aos alunos, que deveriam devolvê-lo em data que antecedesse o dia da pesquisa devidamente assinado pelo próprio aluno e por seu responsável. A seleção dos alunos foi feita por meio de sorteio entre todos os que tivessem autorização para participar e que estivessem presentes no dia. No caso de não haver mais de dez alunos com termos assinados e com aceite, todos os que estavam presentes participaram da pesquisa.

Tomamos algumas precauções, como entregar os Termos de Consentimento Livre e Esclarecido para todas as turmas de nono ano, solicitar a devolução dos mesmos com antecedência mínima de dois dias, fazer contato telefônico com a escola para confirmar a pesquisa e para levantar a quantidade de Termos de Consentimento Livre e Esclarecido devolvidos. Ainda assim tivemos dificuldades. O número de Termos de Consentimento Livre e Esclarecido que retornou foi pequeno, principalmente por parte dos meninos. Podemos supor que o assunto pode ter intimidado a participação deles na pesquisa. Esse fato nos impossibilitou, em alguns casos, de realizar grupos mistos (meninos e meninas). Em apenas três dos sete grupos realizados foi possível ter a participação de meninos e de meninas em igual número, intenção que tínhamos no início do estudo. Dos 53 alunos que participaram do trabalho, 40 eram meninas e 13 meninos.

\section{Grupos focais}

Para trabalhar com as representações sociais do corpo na perspectiva dos adolescentes usamos a técnica de grupo focal 20 e, ao final, solicitamos que cada um preenchesse um instrumento com informações referentes à idade, situação de moradia, condições socioeconômicas, alimentação e imagem corporal, a fim de possibilitar a 


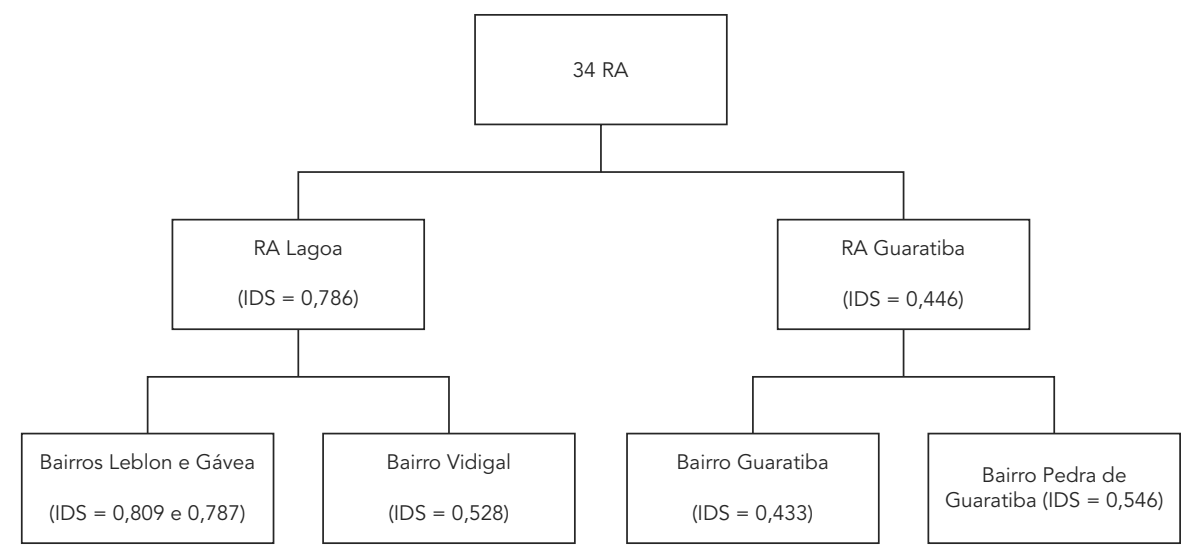

IDS: Índice de Desenvolvimento Social; RA: Região Administrativa.

Fonte: Instituto Brasileiro de Geografia e Estatística. Censo demográfico 2000. http://www.ibge.gov.br/home/estatistica/ populacao/censo2000/default.shtm (acessado em Fev/2009). Instituto Pereira Passos. Armazém de dados. Apresenta estatísticas municipais. http://www.armazemdedados.rio.rj.gov.br (acessado em 10/Jun/2009).

caracterização do contexto socioeconômico em que os sujeitos do estudo viviam e de algumas práticas cotidianas referentes à alimentação e ao seu corpo.

Definimos que seria feito pelo menos um grupo focal em cada uma das escolas onde os alunos participantes estudavam, em local previamente definido junto à direção. Cada grupo realizado foi composto por 7 a 12 pessoas (incluindo o pesquisador e o observador) e não ultrapassou uma hora e cinquenta minutos de duração. A discussão realizada nos grupos focais foi gravada com a concordância dos jovens, após serem informados sobre o sigilo em relação à escola e aos alunos na apresentação dos resultados da pesquisa.

Iniciamos os grupos com a apresentação da pesquisa e dos membros presentes, seguida da dinâmica de evocação de palavras, utilizada como aquecimento para a discussão. Nessa etapa, solicitamos que cada aluno escrevesse em um pedaço de papel até cinco palavras que vinham à cabeça quando ouviam a palavra "corpo". Com base nessas palavras, conduzimos toda a discussão sobre o corpo. Após cada grupo focal foi realizada a transcrição verbatim.

\section{Análise}

Para a análise estrutural das palavras evocadas utilizamos o programa Ensemble de Programmes
Permettant L'Analyse dês Évocations (EVOC) 21, desenvolvido por pesquisadores franceses. O EVOC é uma ferramenta estatística capaz de identificar a organização interna de uma representação social, ou seja, os elementos central e periféricos 21, permitindo sistematizar as palavras enunciadas com base em um conjunto de parâmetros: frequência mínima, frequência média e ordem média de evocação. Os parâmetros adotados para definir os pontos de corte de ordem média de evocação e frequências são baseados nos dados empíricos de cada estudo, pois ainda não se tem consenso a respeito do tamanho da amostra, total de evocações, frequências mínima e média de evocações, e o ponto de corte utilizado para estas frequências 22 .

Com base nesses parâmetros, a ferramenta gera um quadrante com quatro casas que compõem o núcleo central e três periferias. O núcleo central contempla palavras que têm ordem média de evocação menor que o ponto de corte estabelecido e frequência média alta (citadas muitas vezes); na periferia 1 estão as palavras também citadas muitas vezes, mas em últimas posições (maior que o ponto de corte estabelecido para a ordem média de evocação); a periferia 2, palavras citadas em últimas posições (maior que a ordem média de evocação) e um número de vezes compreendido entre o ponto de corte estabelecido para as frequências mínima e média; e na peri- 
feria 3 estão as palavras menos citadas e em últimas posições das cinco palavras evocadas.

Antes de incluir as palavras evocadas no programa, agrupamos as mesmas conforme critério de flexão de número e a sinonímia. Feito isso, tivemos um total de 248 palavras evocadas nos sete grupos focais realizados, sendo 128 diferentes, com média de evocações de 4,7 por sujeito. A frequência mínima considerada para a análise foi quatro e a frequência média igual a sete, valores estipulados de acordo com a recomendação de Wachelke \&Wolter ${ }^{22}$. Esses autores sugerem que o ponto de corte da ordem média de evocação seja igual à metade da frequência das palavras evocadas, ou seja, se são solicitadas aos alunos cinco palavras, a mediana do número de evocações e a ordem média de evocação é três (por arredondamento). A ordem média de evocação indica em que faixa de evocação a palavra foi citada. Por exemplo, a ordem média de evocação igual a três sinaliza que as palavras presentes no lado esquerdo do quadrante (núcleo central e perifeiria 2) foram evocadas nas primeiras e segundas posições. Nas casas do lado direito (periferias 1 e 3) estão as palavras citadas na terceira posição ou acima.

Neste estudo, ao considerarmos a mediana do número de evocações como a ordem média de evocação, verificamos que em relação às ocorrências o número de palavras localizadas nas casas de alta frequência do quadrante destoava das outras casas. Por esse motivo, utilizamos o outro procedimento indicado por Wachelke \&Wolter 22 como opção para a definição de ponto de corte. Consideramos apenas o equilíbrio numérico entre as palavras do núcleo central e periferia 2, utilizando ordem média de evocação igual a 2,40. Esse valor indica que no núcleo central e na periferia 2 estão as palavras que foram citadas como a primeira ou a segunda entre as cinco palavras escritas pelos adolescentes.

Uma vez que a análise prototípica (análise feita a partir da evocação de palavras) "não permite uma varredura completa do campo representacional" 22 (p. 522), e que o programa não substitui o trabalho de interpretação, a análise de conteúdo temática 23 foi utilizada para a interpretação das falas obtidas nos grupos focais.

Com base na leitura do material produzido pelas transcrições dos grupos focais foram identificados os "núcleos de sentido" no texto produzido 23 . No processo de organização e análise desses núcleos de sentido reagrupamos progressivamente as categorias mais fracas, segundo exclusão mútua e a pertinência aos objetivos do estudo e à literatura disponível, obtendo ao final uma única categoria. As citações de falas e palavras mencionadas pelos adolescentes estão evidenciadas em itálico ao longo do texto e a categoria, em negrito.

Cabe ressaltar que a maior parte dos trabalhos já realizados sobre o corpo aborda os adultos, principalmente mulheres 6,24,25. Por esse motivo, o referencial teórico sobre corpo apresenta limitações no que se refere ao corpo masculino e de jovens. Assim, buscamos autores clássicos como Le Breton ${ }^{9}$ e Bourdieu 26 para nossa análise.

\section{Aspectos éticos}

Foram respeitadas as orientações previstas na Resolução no 196/1996 do Conselho Nacional de Saúde no que concerne aos aspectos éticos. O projeto foi aprovado pelo Comitê de Ética e Pesquisa da Secretaria Municipal de Saúde e Defesa Civil do Rio de Janeiro (parecer no 241A/2009) e recebeu parecer favorável da Secretaria Municipal de Educação do Rio de Janeiro. Participaram do estudo somente os adolescentes que apresentaram Termo de Consentimento Livre e Esclarecido assinado, e seu anonimato, bem como o da escola, foram assegurados.

\section{Resultados}

\section{A aproximação com o campo}

Em geral, as escolas visitadas eram bem estruturadas e atendiam aos adolescentes que moravam em área próxima a elas.

Para a realização do grupo focal foram utilizados espaços como sala dos professores ou da coordenação, salas de aula, refeitório (fora do horário do almoço), sala de leitura ou de informática. A sala dos professores e o refeitório não foram os espaços que consideramos apropriados para tal atividade, visto que qualquer ruído ou a entrada de pessoas externas ao grupo de alunos influenciou negativamente na atividade.

Em relação aos sujeitos do estudo, cinquenta e três alunos participaram dos grupos focais, sendo 27 adolescentes de escolas públicas e 26 de escolas privadas. Um aluno de escola pública foi excluído da análise do questionário, uma vez que não estava contemplado na faixa etária estudada. A faixa etária dos alunos variou de 13-18 anos de idade, com média de 15,4 anos entre os estudantes das escolas públicas e 14,5 entre os alunos de escolas privadas.

\section{"O que vem à cabeça quando você ouve a palavra corpo?"}

O que torna interessante a análise estrutural das representações sociais é a possibilidade de iden- 
tificar as nuances que o corpo assume na visão dos adolescentes. Para eles o corpo é o lugar no qual vivenciam o belo e o sensual, mas também é uma fonte de preocupação no que se refere a sua forma física, inquietação comum nesta fase da vida em que as transformações físicas e instabilidades emocionais são uma constante, como descrito por Ferreira \& Leite 12 e Campagna \& Souza 2

Nesse item mostraremos como esse corpo, repleto de mudanças comuns na adolescência, é representado pelos alunos por meio da análise dos elementos constituintes das representações sociais (núcleos central e periféricos), conforme resultados do EVOC. E, para fundamentar os dados, nos apoiaremos na análise das falas dos grupos focais e nos achados da literatura.

Com base na análise das casas da Tabela 1 , observamos que beleza e saúde, além de partes do corpo, como barriga e boca, possivelmente referem a elementos centrais das RS do corpo dos adolescentes estudados. Por fazerem parte do núcleo central, essas palavras merecem destaque, pois indicam que foram citadas com uma frequência acima da média e prontamente evocadas, ou seja, são palavras consensuais que estão mais presentes no dia a dia e na memória desses jovens. Expressam as condições históricas, sociais e ideológicas, associadas diretamente à identidade, às normas sociais e aos códigos culturais que definem o seu modo de vida e constituem as representações do corpo. O elemento pernas, embora não fizesse parte do núcleo central por apresentar a ordem média de evocação mais alta que o ponto de corte $(\geq 2,4)$, merece atenção por também ter tido alta frequência de evocação e, principalmente, por estar presente nas discussões posteriores à dinâmica.

As falas dos jovens nos grupos focais reforçaram o que encontramos como núcleo central e periferia 1 das representações sociais. Na análise temática identificamos como única categoria o corpo belo, que proporcionou a discussão dos seguintes temas: as representações e os padrões de beleza, as insatisfações com o corpo e as cirurgias plásticas como estratégias de modelagem do corpo, as práticas de controle de peso, entre elas a alimentação e a atividade física.

Embora a palavra corpo faça menção a algo mais concreto, que é palpável, surgiu nos grupos palavras associadas a valores, tais como amor, sofrimento e caráter. Porém, os adolescentes expressaram as suas preocupações em atender a um modelo reproduzido pela sociedade que valoriza mais uma forma física do que valores individuais. Praticamente todos os adolescentes falaram da beleza como sinônimo de corpo bonito ou de padrão estético, e descreveram um modelo de beleza diferenciado conforme o sexo: o corpo definido por músculos para os jovens e o corpo magro, sem barriga e com pernas torneadas para as jovens. Um corpo que não tinha na magreza extrema sua associação à beleza, mas em suas formas curvilíneas, com barriga sarada, cintura fina, nádegas e seios grandes, pernas grossas sem exageros. Para as adolescentes a magreza em excesso estava associada às modelos de passarela, ao radicalismo, representado pelos transtornos

Quadrante das representações sociais do corpo por adolescentes, gerado pelo Programa EVOC. Rio de Janeiro, Brasil, 2010.

\begin{tabular}{|c|c|c|c|c|c|c|}
\hline \multirow[t]{3}{*}{ Frequência média } & \multicolumn{6}{|c|}{ Ordem média de evocação } \\
\hline & \multicolumn{3}{|c|}{$<2,4$} & \multicolumn{3}{|c|}{$\geq 2,4$} \\
\hline & Núcleo central & Frequência & $\begin{array}{l}\text { Ordem média } \\
\text { de evocação }\end{array}$ & Periferia 1 & Frequência & $\begin{array}{l}\text { Ordem média } \\
\text { de evocação }\end{array}$ \\
\hline & Beleza & 19 & 2,000 & Perna-s & 12 & 2,667 \\
\hline & Saúde & 10 & 2,200 & & & \\
\hline \multirow[t]{4}{*}{$\geq 7$} & Boca & 8 & 2,125 & & & \\
\hline & Barriga & 7 & 2,143 & & & \\
\hline & Periferia 2 & & & Periferia 3 & & \\
\hline & Movimento & 4 & 1,250 & Braços & 6 & 2,833 \\
\hline \multirow[t]{3}{*}{$4 \leq$ frequência $\leq 6$} & & & & Cabeça & 5 & 2,400 \\
\hline & & & & Comida & 5 & 2,400 \\
\hline & & & & Olhos & 4 & 5,000 \\
\hline
\end{tabular}


alimentares (anorexia, bulimia). Diferentemente de outros momentos históricos, em que a beleza estava associada a corpos robustos 27 , hoje a beleza está associada ao corpo magro e definido 28 .

Segundo estudo realizado por Santos 6 com homens e mulheres, a barriga flácida ou protuberante era interpretada como símbolo de decadência, sedentarismo e não conformação com o mundo contemporâneo. Para sentiremse incluídas nos padrões estéticos estabelecidos (e reproduzidos) pela sociedade, as mulheres procuravam enrijecer seus músculos nas partes inferiores do corpo e, os homens, nas partes superiores. Nosso estudo, embora voltado para adolescentes, corrobora os achados de Santos 6 . As mulheres pareceram mais preocupadas em modelar partes do corpo como as pernas, e os homens mostraram a necessidade de modelar braços e tórax, o que na prática está subentendido na expressão "definir" determinada parte do corpo. Esses achados têm relação com o que Le Breton 29 (p. 9) denomina "corpo socialmente modulável" ao abordar o corpo como algo capaz de refletir as origens e crenças de uma sociedade por meio dos gestos, da maneira de se vestir, da aparência e das práticas corporais. Assim, o corpo não pertence apenas ao sujeito e nem segue apenas os seus desejos, e sim os aceitos pela sociedade.

Para a reflexão sobre a valorização que esse corpo belo representa nas relações sociais adotamos o referencial de Bourdieu 26. Nas falas dos participantes o corpo belo estava carregado de simbolismo capaz de torná-lo um capital simbólico que conferia prestígio ao indivíduo, e assim, possibilitava sua distinção nas relações sociais. Com esse corpo belo, seu potencial para conquistar um emprego, um(a) namorado(a) e ser capaz de provocar o desejo no outro (seja o outro quem for, homem ou mulher) aumentava. Isso quer dizer que um corpo belo é um elemento fundamental para a idealização do que vem a ser considerado sucesso na vida profissional e amorosa para esses jovens.

O corpo belo como capital nos remete ao fato de que este corpo pode "comprar simbolicamente" o projeto idealizado de sucesso, ainda que isto tenha de ser alcançado à custa de muito investimento (capital financeiro) e de sacrifícios. Da mesma forma que em nosso estudo, um outro realizado com adolescentes demonstrou que, no discurso feminino, existe forte relação do corpo e da beleza com o sucesso profissional e na vida ${ }^{3}$.

Para construir o corpo belo e, assim, aumentar seu capital simbólico, o jovem tem hoje diversos recursos disponíveis no mercado para corrigir o que seriam "imperfeições” (o que está fora deste padrão) e potencializar esse modelo de corpo belo ao gosto do dia 29 . As cirurgias plásticas com finalidades estéticas e os transtornos alimentares (bulimia e anorexia) estiveram presentes nos discursos dos jovens ao falarem da "adequação do corpo" ao modelo atual de corpo belo. No entanto, posicionaram-se contra algumas dessas práticas por considerarem uma "preocupação exagerada com a forma física, além de ser prejudicial à saúde".

Percebemos que o modelo de corpo saudável ficou distante da representação de saúde, que inicialmente esteve associada à ausência de doença e, com o aprofundamento da análise, observamos uma visão da saúde que incorporava fatores psicológicos, como o verbalizado no seguinte fragmento "estar de bem com a vida" e consigo mesmo.

De acordo com Siqueira \& Faria 30 , atualmente o modelo ocidental de saúde está na apresentação pública de um corpo definido por músculos rígidos. Mas, diferentemente dessa assertiva, embora os jovens de nosso estudo tenham mostrado que o principal objetivo de fazer atividade física está ligado quase que exclusivamente ao “desejo de ganhar massa muscular", eles consideraram saudável a prática de exercício físico, e não a forma física alcançada com a atividade - o corpo musculoso. Esse corpo que tem uma prática saudável (fazer atividade física), também foi confundido (ou estava imbricado) com o que os adolescentes consideraram o corpo belo. Provavelmente essa confluência entre saúde, atividade física e corpo belo definiu a posição da palavra movimento na periferia 2. Embora tenha sido menos citada (abaixo da frequência média), ocupou os primeiros lugares entre as cinco palavras evocadas. Pela posição ocupada (sistema periférico), podemos dizer que a preocupação dos jovens com o movimento (manter o corpo em movimento, ativo) faz parte das histórias individuais destes jovens, e não necessariamente é uma norma consolidada no seu meio (de iguais), e que é mais sensível ao contexto e, por isto, mais flexível e móvel. Pode mudar conforme a influência da moda, da mídia, da mudança do padrão estético ou por algum acontecimento que faça parte da experiência individual.

Os jovens apontaram o exercício como outro caminho para chegar ao corpo belo (o corpo desejado) e à saúde. A insatisfação com a imagem corporal foi citada por Mattos \& Luz 31 como um dos principais estímulos para a prática de atividade física, principalmente no sexo masculino. Os homens falaram do desejo em ganhar massa muscular, perder peso ou evitar o ganho e da prática como lazer. As mulheres falaram da necessidade da atividade para perder peso, definir alguma parte do corpo (como perna, por 
exemplo), deixar o corpo bonito ou por ser um hábito saudável. Lembramos que, ao evocarem a palavra braços (na periferia 3), a definição desta parte do corpo com músculos pode estar aqui sendo contemplada. No estudo de Braga et al. 3 , por exemplo, os adolescentes também referiram desejar um corpo mais definido e valorizaram, entre outras partes, os braços.

No grupo focal em que o corpo saudável foi mencionado como sinônimo de corpo belo, os jovens alertaram para o fato de que o contrário nem sempre era verdadeiro. Ter um corpo bonito não necessariamente era indicativo de saúde. Pelo que percebemos, a diferença entre um corpo belo e um corpo saudável passava por uma relação direta e indissociável entre corpo, alimentação e saúde, como mencionado na seguinte fala: "O que a gente come vai influenciar no nosso corpo. Mas também o que a gente deixa de comer - coisas saudáveis - também vai influenciar. Joana [nome fictício] teve anemia. Por que ela teve anemia? Trocava o almoço pelo hambúrguer, né? [...]" (GF5).

Esse corpo saudável a que estamos nos referindo, na verdade, é uma reconstrução constante, muitas vezes influenciada pela indústria da beleza a qual tende a associar a forma física saudável à beleza do corpo. Para os jovens de ambos os sexos, o corpo saudável também esteve relacionado à forma física, ao "capital-aparência", como denominado por Malysse 32 (p. 116). O cuidado com a saúde, a "malhação", a "boa alimentação" e o "cuidado com a pele" foram algumas das formas citadas para cuidar do corpo e torná-lo saudável. "Dormir bem", "não beber", "não fumar", "não usar drogas e ir ao médico regularmente" foram alguns dos cuidados citados pelos jovens e que são uma forma de "disciplina", tal como evidenciado no estudo de Braga et al. 3 .

Devido à pressão que sofrem para ter um corpo belo e se aproximarem do padrão estético disseminado como ideal, as jovens sentemse obrigadas a seguir as dietas milagrosas com a finalidade de perder peso rapidamente, mas, por outro lado, são bombardeadas com propagandas de alimentos ricos em calorias e altamente processados. Cria-se então uma zona de conflito entre alcançar o corpo desejado e o sentimento de culpa em se render à indústria de produtos calóricos.

Palavras como "braços", "cabeça”, "comida" e "olhos" compõem a periferia 3 das representações sociais, indicando sua vulnerabilidade a mudanças. Para tentarmos explicar o contexto em que a palavra cabeça foi citada, analisamos as outras evocações feitas por esses alunos e observamos que o sentido dado a ela estava nos aspectos biológicos; nela como uma parte do corpo, e não fazendo parte das representações de corpo belo.

A palavra "olhos", neste estudo, pode representar tanto a importância deste órgão do corpo para os adolescentes, como também a valorização deste em olhar o outro ou o olhar do outro sobre si mesmo. Como mencionado anteriormente ao falar de capital simbólico e prestígio, atrair os olhares foi legitimado pelos adolescentes como um prestígio de possuir um corpo belo. No entanto, por estar na periferia do quadrante, pode indicar não um consenso entre os jovens, e sim demonstrar um subgrupo que valoriza os olhos, dentre os aspectos a observar no outro.

Não observamos diferenciações nos discursos das jovens de diferentes níveis socioeconômicos quanto aos cuidados estéticos, uma vez que todas elas valorizaram o cuidado com o corpo, seja por meio das maquiagens, dos cremes, dos tratamentos da pele, uso de perfumes ou de vestimentas.

Especialmente em um grupo realizado numa escola pública, a forma de se apresentar para o outro e de expressar seus valores passou pelo uso da roupa e, consequentemente, pela forma de apresentação do corpo. As falas dos jovens explicitaram o quanto a apresentação física foi valorizada como preditivo da moralidade, tanto negativa quanto positivamente, como mencionado por Le Breton 29. O limite entre a sensualidade e a vulgaridade apresentou uma forma tênue quando relacionado ao modo de se vestir. Segundo os adolescentes, essa fronteira é estabelecida pelos locais em que as vestimentas são usadas, as combinações ou o tamanho da roupa (muito curta ou muito decotada).

Somado a essa relevância conferida à aparência, não podemos deixar de contextualizar o espaço geográfico em que os adolescentes deste estudo vivem. $\mathrm{O}$ fato de morarem em uma cidade litorânea influencia a apresentação do corpo em público e dita algumas normas e performances específicas. Por ser o corpo o próprio "cartão de visitas vivo", segundo Le Breton 29 (p. 78), isto o torna alvo de julgamentos ao expô-lo, por exemplo, de biquíni. Meninas e meninos do estudo demonstraram preocupação/vergonha em tirar a camisa na praia ou ficar de biquíni. Segundo Goldenberg \& Ramos 33 (p. 334), o corpo carioca desnudado deve estar em conformidade com as regras da "moral da boa forma". Ele precisa estar livre de "gordura, flacidez e moleza" para ser apreciado.

Diversas outras palavras como “órgãos”, “estria”, “celulite”, “espinhas”, “gordo”, “magro”, sentimentos (como "amor", "sofrimento" e "ódio"), valores (como "respeito" ou "caráter") e doença foram evocadas durante a dinâmica, porém, após 
análise por meio do EVOC, estas não fizeram parte das representações sociais do corpo para os adolescentes. Ou seja, não estiveram presentes na organização interna das representações.

\section{Considerações finais}

Características do corpo como objeto de consumo, a preocupação excessiva com a aparência e o discurso pautado pela mídia na definição de padrões estéticos de beleza e de saúde, estiveram presentes nas falas dos jovens que participaram deste estudo. E, embora o corpo seja individual e singular, o discurso retratou a existência de um padrão estético hegemônico para as mulheres belo, magro e definido, e para os homens - belo e musculoso.

A importância atribuída à beleza nos levou a discuti-la como um capital-simbólico, no qual, para estes jovens, o fato de conseguir um emprego, um parceiro/parceira ou atrair os olhares do outro pareceram ser alguns dos prestígios conquistados com o corpo belo. Além disso, a relevância do padrão estético refletiu nos jovens, que trouxeram para a discussão sentimentos de discriminação e preconceito, especialmente aqueles que se sentem fora do modelo reproduzido pela sociedade. Observamos nas falas que o estereótipo de beleza faz do corpo algo que carrega um valor moral e que pode ser moldado confor- me o que é socialmente aceito. A presença de um padrão estético hegemônico não é um problema em si, mas pode vir a ser quando os jovens não conseguem atendê-lo e resolvem realizar práticas prejudiciais à saúde.

Para que tenhamos sucesso nesse árduo desafio de conhecer os aspectos subjetivos da imagem corporal, é necessário refletirmos sobre alguns posicionamentos que a sociedade assumiu como adequadas e sobre as normas e recomendações "mágicas" de emagrecimento imediato, alimentação saudável e construção de um corpo bonito.

A aproximação das representações sociais dos adolescentes sobre o corpo contribui para repensarmos as práticas dentro da escola, para que criem oportunidades de conversar sobre o corpo, estigma e transtornos alimentares dentro e fora da sala de aula. Dada a influência da mídia na construção cultural do padrão estético, a regulamentação de propagandas dirigidas ao público infanto-juvenil seria uma iniciativa importante de promoção da saúde e de esforço para evitar as consequências das insatisfações corporais. É necessário que o desenvolvimento dos jovens seja acompanhado de perto (pela família e pela escola, por exemplo) e que cada cidadão colabore na construção de uma sociedade mais respeitosa e acolhedora com as pessoas e suas singularidades, especialmente no que diz respeito ao corpo.

\section{Resumen}

La adolescencia es una etapa de la vida con cambios corporales que parece adquirir una importancia primordial. Para abordar los conflictos experimentados por los adolescentes con sus cambios corporales, este estudio tuvo como objetivo identificar las representaciones sociales del cuerpo de los adolescentes en el noveno año de escuela primaria en las redes de educación privadas y públicas (municipales) de Río de Janeiro, Brasil. Los participantes tenían entre 13 y 18 años y estudiaban en las escuelas ubicadas en vecindarios con los valores más altos y más bajos del Índice de Desarrollo Social. Se utilizó la técnica de grupo focal para la producción de la representación social del cuerpo. Cada grupo comenzó con la selección de cinco palabras al oír la palabra "cuerpo". Para el tratamiento de evocaciones, se utilizó el programa EVOC y se complementó con un análisis de contenido temático. Gran parte de los adolescentes habló de la belleza como sinónimo de cuerpo hermoso y describen un modelo de belleza: el cuerpo se define por los músculos para el cuerpo joven y delgado $y$ con curvas para las chicas.

Imagem Corporal; Adolescente; Grupos Focales 


\section{Colaboradores}

M. D. Passos contribuiu no delineamento do estudo, participou do trabalho de campo, da análise dos grupos focais e da redação do manuscrito. S. A. Gugelmin contribuiu no delineamento do estudo, colaborou na análise dos grupos focais e na redação do manuscrito. I. R. R. Castro contribuiu no delineamento do estudo e colaborou na redação do manuscrito. M. C. V. S. Carvalho colaborou na análise dos grupos focais e na revisão do manuscrito.

\section{Agradecimentos}

Ao Instituto de Nutrição Annes Dias pelo apoio logístico para a realização do trabalho de campo.

\section{Referências}

1. Faria L. Desenvolvimento do auto-conceito físico nas crianças e nos adolescentes. Análise Psicológica 2005; 4:361-71.

2. Campagna VN, Souza ASL. Corpo e imagem corporal no início da adolescência feminina. Bol Psicol 2006; 56:9-35.

3. Braga PD, Molina MCB, Figueiredo TAM. Representações do corpo: com a palavra um grupo de adolescentes de classes populares. Ciênc Saúde Coletiva 2010; 15:87-95.

4. Wolf N. O mito da beleza: como as imagens de beleza são usadas contra as mulheres. Rio de Janeiro: Editora Rocco; 1992.

5. Conti MA, Frutuoso MF, Gambardella AMD. Excesso de peso e insatisfação corporal em adolescentes. Rev Nutr 2005; 18:491-7.

6. Santos LAS. O corpo, o comer e a comida: Um estudo sobre as práticas corporais e alimentares cotidianas a partir da Cidade de Salvador-Bahia. 2006 [Tese de Doutorado]. São Paulo: Pontifícia Universidade Católica de São Paulo; 2006.
7. Multirio - Empresa Municipal de Multimeios. A civilização das formas: o corpo como valor. http:// portalmultirio.rio.rj.gov.br/sec21/chave_artigo. asp?cod_artigo=1156 (acessado em 01/Out/2010).

8. Multirio-Empresa Municipal deMultimeios. Corpo reafirma a identidade do jovem. http://portalmulti rio.rio.rj.gov.br/sec21/chave_artigo.asp?cod_arti go=1081 (acessado em 01/Out/2010).

9. Le Breton D. Adeus ao corpo: antropologia e sociedade. 3a Ed. São Paulo: Papirus; 2008.

10. Novaes JV. O intolerável peso da feiúra: sobre mulheres e seus corpos. Rio de Janeiro: Editora PUC Rio; 2006.

11. Sociedade Brasileira de Cirurgia Plástica. Cirurgia plástica no Brasil. São Paulo: Datafolha Instituto de Pesquisas; 2009.

12. Ferreira MC, Leite NGM. Adaptação e validação de um instrumento de avaliação da satisfação com a imagem corporal. Avaliação Psicológica 2002; 2:141-9. 
13. Nunes MA, Olinto MTA, Barros FC, Camey S. Influência da percepção do peso e do índice de massa corporal nos comportamentos alimentares anormais. Rev Bras Psiquiatr 2001; 23:21-7.

14. Secretaria Municipal de Saúde e Defesa Civil. Monitoramento da Saúde Escolar 2007. Rio de Janeiro: Secretaria Municipal de Saúde e Defesa Civil; 2011.

15. Instituto Brasileiro de Geografia e Estatística. Pesquisa Nacional de Saúde do Escolar. Rio de Janeiro: Instituto Brasileiro de Geografia e Estatística; 2009.

16. Moscovici S. A representação social da psicanálise. Rio de Janeiro: Jorge Zahar Editores; 1978.

17. Sá CP. Núcleo central das representações sociais. Petrópolis: Editora Vozes; 2002.

18. Abric J-C. A abordagem estrutural das representações sociais. In: Moreira ASP, Oliveira DC, organizadores. Estudos interdisciplinares de representação social. Goiânia: Editora AB; 2000. p. 27-38.

19. Instituto Pereira Passos. Armazém de dados. Apresenta estatísticas municipais. http://www. armazemdedados.rio.rj.gov.br (acessado em 10/ Jun/2009).

20. Gatti BA. Grupo focal na pesquisa em Ciências Sociais e Humanas. Brasília: Líber Livro Editora; 2005.

21. Vergès P. Ensemble de programmes permettant l'analyse des evocations. Aix-en-Provence: Université de Provence; 2005.

22. Wachelke J, Wolter R. Critérios de construção e relato da análise prototípica para representações sociais. Psicol Teor Pesqui 2011; 27:521-6.
23. Bardin L. Análise de conteúdo. 3ạ Ed. Lisboa: Edições 70; 2010.

24. Del Priore M. Corpo a corpo com a mulher: pequena história das transformações do corpo feminino no Brasil. São Paulo: Senac São Paulo; 2000.

25. Vilhena J, Medeiros S, Novaes JV. A violência da imagem: estética, feminino e contemporaneidade. Revista Mal-Estar e Subjetividade 2005; 5:109-44.

26. Bourdieu P. O capital simbólico. In: Bourdieu P, organizador. O senso prático. Petrópolis: Editora Vozes; 2009, p. 187-202.

27. Contreras J. La obesidad: una perspectiva sociocultural. Formación Continuada en Nutrición y Obesidad 2002; 5:275-86

28. Mattos R. Sobrevivendo ao estigma da gordura. São Paulo: Vetor; 2012.

29. Le Breton D. A sociologia do corpo. Petrópolis: Editora Vozes; 2010.

30. Siqueira DCO, Faria AA. Corpo, saúde e beleza: representações sociais nas revistas femininas. Comunicação, Mídia e Consumo 2007; 4:171-88.

31. Mattos RS, Luz MT. Sobrevivendo ao estigma da gordura: um estudo socioantropológico sobre obesidade. Physis (Rio J.) 2009; 19:489-507.

32. Malysse S. Em busca dos (H)alteres-ego: olhares franceses nos bastidores da corpolatria carioca. In: Goldenberg M, organizador. Nu \& vestido: dez antropólogos revelam a cultura do corpo carioca. Rio de Janeiro: Editora Record; 2002. p. 79-138.

33. Goldenberg M, Ramos MS. A civilização das formas: o corpo como valor. In: Goldenberg M. Nu \& vestido: dez antropólogos revelam a cultura do corpo carioca. Rio de Janeiro: Editora Record; 2002. p. 19-40.

Recebido em 08/Fev/2013

Versão final reapresentada em 09/Jun/2013

Aprovado em 12/Jul/2013 